\title{
Tics and Tourette Syndrome - Key Clinical Perspectives: Roger Freeman (ed)
}

\author{
Published by Mac Keith Press, London; First Edition: 2015; ISBN: 978-1-909962-41-5
}

\author{
Sheffali Gulati ${ }^{1}$
}

Received: 2 June 2016 / Accepted: 2 June 2016 /Published online: 11 June 2016

(C) Dr. K C Chaudhuri Foundation 2016

Tic disorder is a common neurodevelopmental disorder of childhood. It is one of the commonest condition encountered by a pediatrician in office practice, especially in developed countries. Tics, being a chronic morbidity requires long term follow up not just with a pediatrician but also with a team of experts comprising of neurologist, physiatrist, occupational and speech therapist. The pathophysiology and etiology of this disorder is largely elusive and that is why there is a lack of awareness about this disorder among general public as well as among majority of pediatricians. However, a book which comprehensively covers all aspects of this interesting but difficult to manage condition of tic disorders was lacking. This book entitled, 'Tics and Tourette syndrome' by Dr. Roger Freeman and published by Mac Keith Press is a welcome step in this direction. It covers extensively all possible aspects of Tic disorders including history, etiopathogenesis, comorbidities, diagnostics, therapeutics, and prognosis.

The section on management is very elaborate and comprehensive. It enumerates in detail the multidisciplinary management that should be ideally followed in a Tic disorder. The treatment scope and goals described with each modality of treatment are very impressive. The highlights of this book are case based examples and practice points which make this book distinct from other books. Co-morbidities of tic disorders are dealt separately and elaborately, which adds to uniqueness of this book. The management aspect of various co-morbidities has also been discussed in depth. These descriptions are very useful as they mention the latest consensus guidelines and provide the level of evidence. There is also a separate section which describes the various experimental modes of therapy currently being investigated and their current status and application in management of tic disorders. The author has also incorporated family focussed intervention which is very important as family plays the pivotal role in the holistic management of a patient with tic disorder.

This book has the capacity to address a wide audience that includes practising pediatricians, faculty who teach developmental pediatrics, psychiatry, adolescent medicine and in turn, most importantly helping a child with a Tic disorder to lead a life to the best of their capabilities. A wonderful and easy reading, its recommended for use by all pediatricians.
Sheffali Gulati

sheffaligulati@gmail.com; sheffalig@yahoo.com

1 Child Neurology Division, Department of Pediatrics, All India Institute of Medical Sciences, New Delhi 110029, India 